\title{
On the Beauty of Imagery of Chinese Traditional Animation
}

\author{
Hongjuan Sun \\ Faculty of Art and Design \\ Huanghe Science and Technology College \\ Zhengzhou, China \\ 441356120@qq.com
}

\begin{abstract}
The past glory of China's traditional animation lies within the unique ethnic characteristics of Chinese traditional animated films. Chinese traditional animation has always focused on the innovation of picture forms. The author of this thesis explores, from the perspective of the utilization of traditional Chinese painting in animation, the application of scattered perspective and picture composition in China's traditional animation.
\end{abstract}

Keywords-Chinese traditional animation; flat view composition; scattered perspective; traditional art

\section{INTRODUCTION}

Chinese culture has a long history back to the ancient times, and the same emphasis of traditional Chinese art has always been on spontaneous expression, which consists of multiple forms and has strong ethnic characteristics, and under the influence of which, the styles as well as picture compositions of Chinese traditional animated films have been distinctively different from those of other countries, with rich Chinese national characteristics. For example, China's first color animated feature film, "Havoc in Heaven" has a strong ethnic decorative painting style, and "A Deer of Nine Colors" borrows elements of Dunhuang Grotto Murals of Northern Wei Dynasty. These films create an unparalleled unique visual feast for the audiences. In the era dominated by three-dimensional and computer-aided animation, these animated films still look so beautiful and never cease to deliver amazing viewing experience for people.

\section{THE COMPOSITIONAL CHARACTERISTICS OF CHINESE TRADITIONAL ANIMATION}

The manifestation of Chinese traditional animation varies a lot, such as paper-cuts, ink painting, puppetry and other forms. Chinese animation has a close relationship with Chinese painting, and its art style has great emphasis on the sense of beauty in picture composition as a result of the deep influence of the aesthetic ideology of Chinese painting art. Due to the influence of the Chinese painting style, there is a distinct difference between Chinese animation and those of Japan and the United States. Chinese traditional animation, unlike that of the United States which stresses the authenticity of action and space perspective, emphasizes the aesthetic feeling the picture presents. The animated film "Havoc in Heaven" is highly decorative in its art style and adopts a two-dimensional approach in picture composition. Images in this film have a strong ethnic style, and the scene design has the features of decorative elaborate-style painting. The use of color also has a distinct Chinese flavor, and the character designs and color scheme of the film have also learned from the essence of Chinese printmaking and paper-cuts, and together with the common folk blue, green, red, white, black and other colors, presenting to the audience a feeling that is both common and fresh, both traditional and with refined processing. The picture composition of the film adopts the flat view composition method. Flat view composition is rather a freestyle composition in pattern compositions which does not emphasize the three-dimensional effect in the picture. The majority of picture composition in murals, folk paper-cuts and Chinese painting is flat view composition. The advantage of this composition is that elements are not limited by the size of the frame, nor restricted by the space when presented on the picture, which is suitable for the display of more complex scenes. This composition comes with a high degree of generalization and is very expressive. And with a few simple strokes, images of distinctive personality and complex inner emotions are created. The scene design of "Havoc in Heaven" makes very good use of the flat view composition method. The animated film "A Deer of Nine Colors" also borrows from the artistic expression of such traditional art style. The picture of the film is bold and untrammeled and full of wild imagination and uninhibited force of life, especially where, after the animals led by the deer of nine colors arrive at the land of paradise, flowers of all colors -- crimson, red, blue, pink and white - are blossoming, and even the soils are red; the leaves are green and blue, the deer of nine colors is surrounded by dark-colored butterflies, birds of yellow and red colors and rabbits of red, white and blue. All such varieties of animals and plants are blooming with brilliance and vitality of life. The picture is dominated by a dark tone, with a vigorous deer of nine colors dashing in the middle of the frame. The picture itself becomes a poem in praise of life, and right in here the continuity of the story is temporarily interrupted, showcasing a carefree and unrestrained state of life in the coagulation of time. The film also uses a flat view method in the picture composition which flattens the images and creates a kind of beauty in the imagery for the audiences. For example, a few 
simple lines sketch out a scene of mountains.

Animation composition should break the rules to fully develop their imagination. The main target of animation composition is to solve the relationship between the manifestation style and the content in terms of the aesthesis, rhythm and narrative space, which shall be a relation of mutual reflection. The animation composition and the theme of the film shall share a harmonious unity, with a consideration of the unity of the aesthetics of the pictures and the vividness of the story. Most Chinese traditional animated films have adopted the flat view composition method, which exemplifies an intrinsic linkage with our traditional paintings. Traditional Chinese paintings are influenced by the ideology of the Taoist philosophy which believes that all things are born of "a state of nothingness", which, as a manifestation in paintings, is the use of blankness with a view of expressing the infinity of time and space. With years of development, China's animation has been internationalized and has gradually lost its unique Chinese cultural identity. Modern animation design should combine modern styles with ethnic characteristics. The Japanese animation has been a very good example of reflection of styles of their own ethnic background. The composition of contemporary Chinese animation usually adopts the principle of focus perspective and the shades and gradients of pictures to show the effect of visual space, conjuring a three-dimensional space in a two-dimensional plane. The art forms of Chinese traditional animation, though fully embodying the characteristics of Chinese art, are too decorative in modeling aspects and lack of a sense of intimacy. They should break through the traditional method in modeling aspects and shall be in conformity of modern aesthetic habits and then be combined with composition methods of traditional paintings.

\section{THE PERSPECTIVE CHARACTERISTICS OF CHINESE TRADITIONAL ANIMATION}

Animation art, as the art of painting extended in space, also represents visual spatial form through the use of perspective principles. Chinese traditional animation, in addition to the use of flat view composition in the visual aspects of composition, draws on the characteristics of Chinese painting, using scattered perspective, which moves the visual focus constantly and thus breaks the boundaries of a visual field, adopting the combination of diffused visual approach and multiple visual fields, organizes naturally scenes and objects within one frame of picture. Chinese traditional animation, in using such perspective principle, extremely enhances the freedom in picture composition and renders the picture extremely extensible, reaching a new height in terms of both width and perceptions.

The feature film "Three Monks" reflects a strong Chinese flavor both in terms of the plot and the picture style by drawing on the aesthetic spirit and composition principle of Chinese paintings, which excel at the use of imagery, the scattered perspective and the use of blanks. In the aspects of scene design, the film borrows the philosophy of "knowing and observing all yet staying in obscure" of Chinese painting, utilizing simple props or scenery to explain the environment of the story happening, and thus creating the atmosphere of the film with a few brief pictures. For example, when the first monk enters the view, the back drop is blank; and in the scene a little monk is walking with two birds flying overhead, which allows the viewers to think of an outdoor location where the little monk is walking on a flat ground. Similarly, in the scene where three monks are chanting in the temple, the picture shows nothing taken for granted for such scenes such as the walls of the temple depicted adopting focus perspective, or the image of Buddha Kwan Yin or the pillars of the temple or the like, but a blank screen with only three futons, on top of which sitting three monks chanting. All scenes and objects are erected, with the viewpoint flowing constantly, and the visual angles transforming in turns of eye level, looking up and overlooking angles. With different characters and scenes placed in one picture, the true perspective is broken and all the picture elements are reorganized to achieve a breakthrough of the visual effect.

In this film, in addition to the use of the Chinese painting technique of "knowing and observing all yet staying in obscure", a scattered perspective is also adopted to have the entire picture flatten and the elements in the picture erected. The advantage of the use of such perspective is that the audience can clearly see the action of every character. The traditional Chinese paintings, unlike Western paintings which are made in strict compliance with the focus perspective principle for the purpose of achieving a truthfulness of visual effects, do not pay attention to perspectives. Chinese paintings often use scattered perspective to depict the whole event in one picture. For example, the famous painting of "Riverside Scene at Qing Ming Festival" records the buildings and the people's livelihood along the banks of the Bian River both in the suburbs and city of the capital city of Bian Jing (now Kai Feng) of the era of Emperor Hui Zong of the late Northern Song Dynasty. With a scattered perspective, the prosperity of the entire city is depicted in one single picture. In this way, the limit of the focus perspective, namely the unseen sides, is effectively avoided, and the imagination of the artist is also given a full play, as well as the imagination of the viewers. In modern animation design, such unique perspective principle can also be adopted to focus on the imagery of the picture while completely ignoring principle of the distances, the truthfulness or the sizes, or simply put, to flatten the whole picture and display every side in one frame of picture. By doing so, multiple story lines occurring at the same time can be carried out in the film, which renders flexibility for film editing, leads to convenience for scene switching, as well as benefits the narration of events.

Animated films using scattered perspective, in addition to the rich variation of the scenes, also have the benefit of film montage. Montage, as an original architectural term, was later borrowed into the art of film making which is interpreted as the editing of the screenshots and scene clips. Montage has the ability to manipulate time and space, and through the editing of the screenshots, one can leap backward and forward in time and shift constantly in spaces. For example, in the feature file "Three Monks", the director uses ups and downs of a jumping sun to express the changes of time. The film is also very subtle 
in the expression of the transform of spaces. Instead of switching between different scenes, the film chose to depict, on one blank background, two monks shouldering water buckets one after the other to the left of the picture, and then turn to the right with the switch of the position of the two monks. Through such a clear picture and typical action, viewers can get a clear message of the two characters walking along the hillside, and hence the switching of space was accomplished with a spontaneous expression.

\section{CONCLUSION}

China's traditional animation has a lot of successful works, all of which tapped deep in the essence of the folk art and the traditional Chinese painting, forming a unique style of traditional Chinese animation. The ancient Greek philosopher Aristotle once said: Imagination is the source of all inventions, discoveries and other creative activities. Chinese traditional animation gives full play of the imagination of people. In animated films, Chinese traditional arts are fully integrated in terms of the character modeling, scene designing, and even the animation languages, achieving the ultimate display of the Chinese traditional thinking. Animation as a form of art requires the imagination of the creators. The contemporary animated films emphasize more and more on the realistic style, thus ignoring the integration of traditional Chinese painting art. Director Kexuan Ma once remarked that: animation is not for the pursuit of truthfulness, and if so, the animation would lose the original charm of animation. Virtual reality would only make the audience feel bored and uninteresting. In the animated films, to convey an idea through imagery and to create a distinctive artistic style can give the audience more room for imagination. This is also more in line with the art features of exaggeration and funniness of animated films.

\section{REFERENCES}

[1] Sun Yingli, Chinese Traditional Painting Concept Insinuated in Animated Films [J]. Film Literature, 2010.10

[2] Sun Li, Television Animation Visual Language [M] Beijing : Ocean Press, 2008

[3] Yin Jun Yin. A Comparative Study of Sino-Japanese Animation Art [J]. Suzhou, Suzhou University, 2009

[4] Liu Tao. Research of Applications of Traditional Chinese Cultural and Visual Symbols in the Animation Character Design [J]. Suzhou, Suzhou University, 2010

[5] Zhao Qin, Direction of Nationalization of Chinese Animation Art [J]. Liaoning. Art Grand, 2010.10 